Preliminary communication

\title{
GANGLIOSIDES IN DAIRY PRODUCTS: MILK SPHINGOLIPIDS
}

\author{
S. Ротос̌KI* \\ Department of Chemistry, Biochemistry and Clinical Chemistry, University School of Medicine, Šalata 3, 10000 \\ Zagreb. Croatia
}

(Received: 3 March 2016; accepted: 12 May 2016)

\begin{abstract}
Milk gangliosides have gained considerable attention because they participate in diverse biological processes, including neural development, pathogen binding, and activation of the immune system. The aim of this study was to determine the concentrations of total gangliosides in dairy products and to determine whether there is a significant difference in comparison to concentration of gangliosides in cow's milk. The concentration of total gangliosides in dairy products was significantly higher than concentration in cow's milk. The highest concentration of gangliosides was determined in yogurt with $3.2 \%$ of milk fat.
\end{abstract}

Keywords: gangliosides, sphingolipids, dairy product, milk

The health benefits of milk and fermented milk products have been known since medieval times. Milk is a complex mixture of specific bioactive proteins, lipids, and saccharides. Lipids are secreted in milk in the form of milk fat globules, which are enveloped by a biological membrane known as the milk fat globule membrane (MFGM), (JENSEN \& NEWBURG, 1995). The polar lipid fraction of the MFGM consists of glycerophospholipids and sphingolipids, which may represent the most structurally diverse category of lipids in nature.

Gangliosides are glycosphingolipids, which are expressed more predominantly in nervous tissue and are particularly abundant in brain (KOLTER, 2012). Glycosphingolipids are naturally found in biological fluids, including mammalian milks (LEDEEN \& YU, 1982). They consist of a ceramide core (sphingoid base linked to a fatty acid by an amide linkage) to which glycans are attached through a single glycosidic linkage at the 1-hydroxyl position (Kolter, 2012), (Fig. 1). The glycan chains, based on a combination of glucose, galactose, and $\mathrm{N}$-acetylgalactosamine, contain between 1-4 (and unusually up to 7) sialic residues (SCHNAAR et al., 2014). They are highly heterogeneous, resulting in high structural and functional diversity.

Gangliosides are complex molecules associated with expansive roles in the body. These compounds are critical for the maintenance of membrane structure, modulating the behaviour of growth factor receptors, and serving as binding sites for some microorganisms, microbial toxins, and viruses (VeSPER et al., 1999). Gangliosides play a central role in cell-cell communication, cell-matrix interactions, and growth and differentiation of cells, especially neurons (MCJARROw et al., 2009).

\footnotetext{
* To whom correspondence should be addressed. Phone: +38595 5250 033; e-mail: spotocki@mef.hr
} 


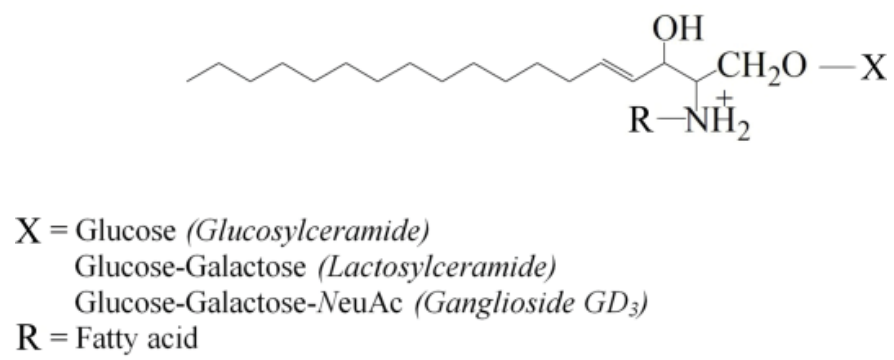

Fig. 1. Structure of gangliosides

Sphingolipids are estimated to constitute $0.01-0.02 \%$ of the human diet with a yearly intake per capita of about $115 \mathrm{~g}$ (VESPER et al., 1999). Most of the sphingolipids consumed per year are derived from dairy products (VESPER et al., 1999).

Although there is emerging evidence suggesting that dietary sphingolipids may prevent development of disease (Vesper et al., 1999; Schmelz et al., 2000; Possemiers et al., 2005; CASTRO-Gomez et al., 2015), the knowledge of their concentrations in food is limited. The aim of this study was to determine the concentrations of total gangliosides in dairy products and to determine whether there is a significant difference in comparison to concentration of gangliosides in cow's milk.

\section{Materials and methods}

\subsection{Samples}

The following dairy products were examined: yogurt $3.2 \%$, yogurt $2.8 \%$, kefir $3.2 \%$, acidophilus milk $3.2 \%$, sour cream $20 \%$, sour cream $12 \%$, sour milk $3.2 \%$, and cow's cheese $15 \%$ milk fat (Dukat Ltd, Zagreb, Croatia).

\subsection{Lipid extraction}

Samples were frozen and lyophilized using a rotary evaporator equipped with a cooling unit. Two millilitres of a mixture of chloroform:methanol:water (v:v:v=4:8:3) was added to the lyophilized sample and left on a laboratory shaker for $1 \mathrm{~h}$. The mixture was then centrifuged, the supernatant was separated, and $1 \mathrm{ml}$ of the same solvent mixture was added to the precipitate. The mixture was left on a laboratory shaker for 1 more $h$ and then it was centrifuged. The supernatants merged and the content of gangliosides was determined within them, while the content of sialoglycoproteins was determined within the precipitate.

\subsection{Quantitative determination of gangliosides}

Four hundred and eighty microlitres of distilled deionized water and $500 \mu 1$ of Svennerholm's reagent were added to $20 \mu \mathrm{l}$ of supernatant, and the mixture was left for $20 \mathrm{~min}$ in a water bath at $100{ }^{\circ} \mathrm{C}$. One and a half millilitres of ethanol:butyl acetate (v:v=15:85) was added to the cooled mixture, it was mixed well, and it was centrifuged for 2 min at 3000 r.p.m. 
Afterwards, the absorbance of the upper phase was read at $580 \mathrm{~nm}$. The concentration of gangliosides was determined by interpolation from a calibration chart prepared with known concentrations of $N$-acetylneuraminic acid $\left(0.1 \mathrm{mg} \mathrm{ml}^{-1}\right)$. Svennerholm's reagent was prepared by mixing $10 \mathrm{ml}$ of $2 \%$ resorcinol, $80 \mathrm{ml}$ of conc. $\mathrm{HCl}, 0.25 \mathrm{ml}$ of $0.1 \mathrm{M} \mathrm{CuSO}_{4}$ and was filled to $100 \mathrm{ml}$ with distilled water. The reagent was prepared at least $4 \mathrm{~h}$ before use and was stable for up to seven days at $4{ }^{\circ} \mathrm{C}$ (Svennerholm, 1957).

\subsection{Quantitative determination of sialoglycoproteins}

One hundred and fifty microlitres of $0.1 \mathrm{M} \mathrm{H}_{2} \mathrm{SO}_{4}$ was added to the residue, stirred, and left for $1 \mathrm{~h}$ at $80^{\circ} \mathrm{C}$. Thereafter it was centrifuged for $10 \mathrm{~min}$ at $6000 \mathrm{r}$.p.m. For the determination of sialic acid liberated from the protein upon the action of $\mathrm{H}_{2} \mathrm{SO}_{4}, 100 \mu$ of supernatant was used, in addition with $10 \mu \mathrm{l} 0.1 \mathrm{M} \mathrm{CaCl}_{2}$ and $20 \mu \mathrm{l} 0.04 \mathrm{M} \mathrm{NaIO}_{4}$, following stirring and leaving in an ice bath for $20 \mathrm{~min}$. At that point, $250 \mu \mathrm{l}$ of resorcinol reagent was added, stirred and left for $5 \mathrm{~min}$ in an ice bath, followed by $15 \mathrm{~min}$ at $100^{\circ} \mathrm{C}$. The mixture was cooled; 250 $\mu 1$ of $t$-butanol was added, stirred and left for $3 \mathrm{~min}$ at $37^{\circ} \mathrm{C}$. After that the absorbance was read at $630 \mathrm{~nm}$ (Jourdian et al., 1971). The concentration of sialoglycoproteins was determined by interpolation from a calibration chart prepared with known concentrations of $\mathrm{N}$-acetylneuraminic acid $\left(0.1 \mathrm{mg} \mathrm{ml}^{-1}\right)$. Resorcinol reagent was prepared by dissolving $0.6 \mathrm{~g}$ of resorcinol in $40 \mathrm{ml}$ of distilled deionized water, $60 \mathrm{ml}$ conc. $\mathrm{HCl}$ and $0.25 \mathrm{ml}$ of $0.1 \mathrm{M}$ $\mathrm{CuSO}_{4}$ (before use).

\subsection{Statistical analysis}

Statistical analysis was performed using the Mann-Whitney test applying the MedCalc software system for data processing (version 10.2.0.0). For the limit of statistical significance the following value was taken: $\mathrm{P} \leq 0.05$.

\section{Results and discussion}

The highest concentrations of gangliosides were found in yogurt with $3.2 \%$ of milk fat, and the lowest in cow's milk (Table 1). Statistically speaking, the concentrations of total gangliosides in dairy products were significantly higher than the ones in cow's milk (Table

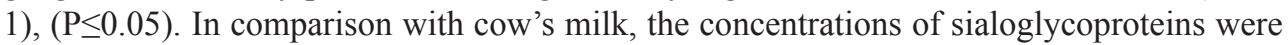
statistically different $(\mathrm{P} \leq 0.05)$ in all dairy products, with the exception of yogurt with $3.2 \%$ of milk fat, sour milk with $3.2 \%$ of milk fat, and acidophilus milk with $3.2 \%$ of milk fat (Table 1). The comparison of medium-concentration values of sialoglycoproteins in particular samples of dairy products shows that they were statistically higher in sour cream with $20 \%$ and $12 \%$ of milk fat and cow's cheese (Table 1), ( $\mathrm{P} \leq 0.05)$. The higher concentration of total gangliosides in dairy products could be the result of the way the milk is processed.

Technological processes used in the dairy industry can affect the structure and composition of milk components and alter their technological and nutritional properties (GARCIA et al., 2014). One of them, homogenization, is defined as the process of subdividing the relatively large polydisperse oil globules of a coarse oil-in-water emulsion into large number of smaller globules of narrow size range. It results in the most profound changes in the physical structure of milk, such as the decrease in fat globules and changes in fat globule surface composition (Lopez, 2005). As homogenization does not kill microorganisms, 
intensive heat treatments (pasteurization or UHT, ultra-high temperature process) are necessary in order to preserve product microbiological quality. Heat treatments are the easiest way to preserve milk, but they enhance the impact of homogenization on the organization of milk, and possibly on its quality and health properties. The consequence of homogenization on the organization of milk depends on the sequence and type of homogenization and heat treatments. The processing of milk affects the microstructure of fat and alters the biological membrane (LopEz et al., 2015). When milk is processed at the dairy, the MFGM is disrupted and, as such, is no longer associated with the fat globules. The size decreases, the surface area increases, and the architecture of the TAG/water interface changes. It was reported that during processing, gangliosides are preferentially distributed to aqueous phases like skimmed milk, buttermilk, and butter serum (RomBAut et al., 2006; LeE et al., 2013). Buttermilk and butter serum are the liquid phases released during churning of cream in the process of butter making and during preparation of anhydrous milk fat. Neutral lipids, such as TAG, are mainly recovered in butter, while the polar lipids organized as vesicles and MFGM fragments are selectively found in the aqueous phases such as buttermilk and butter serum. Buttermilk and butter serum contain about 2 and $11 \% \mathrm{w} / \mathrm{w}$ of polar lipids on dry matter, with 19 and 30\% $\mathrm{w} / \mathrm{w}$ of sphingolipids on polar lipids, respectively (RomBAUT et al., 2006). It is concluded that butter serum, with its high polar lipid and sphingolipid content was the most promising raw material for further purification.

Apart from dietary manipulation, stage of lactation, season, species, and MFGM size are factors that may modify ganglioside content or ganglioside composition in milk. Additionally, the amount of gangliosides also changes with animal species.

On the basis of the obtained results in this work, it can be concluded that if the portion of milk fat in one type of sample is higher, the concentrations of total gangliosides will be higher as well (Table 1). This points to the possible correlation between the amount of lipids and gangliosides in the same type of sample.

Gangliosides are structurally important for modulating receptor function and inflammatory signalling. It is plausible that food sphingolipids can compete for and act as cellular binding sites. Gangliosides are strongly associated with neural functioning. Numerous studies clearly demonstrate the importance of sphingolipid rich foods or supplements as it could be an important mediator in the prevention of colon cancer and bowel-related disease (Schmelz et al., 2000). Few observational findings suggest that dairy food intake may be positively related to cognitive function (CRICHTON et al., 2012). The effects of both dietary intakes of sphingolipids and administration of pharmaceutical preparations have been extensively reviewed (KUCHTA et al., 2012). Knowing potent biological activities of sphingolipids, it is likely that they can be categorized as functional components of food with regard to human health, especially for prevention of colon cancer as well as being a cholesterol-lowering agent ( $\mathrm{NoH} \& \mathrm{KoO}, 2004)$ and protectant against bacterial infections in the gut (Pfeuffer \& Schrezenmeir, 2001). The idea of functional food development inclines towards introducing dairy products enriched in MFGM as a rich source of sphingolipids and phospholipids. 
Table 1. The concentrations of gangliosides and sialoglycoproteins (Mann-Whitney test)

\begin{tabular}{|c|c|c|c|c|}
\hline & $\mathrm{N}$ & Sample & $\mathrm{M}\left(\mathrm{IQR} 25^{\text {th }} ; 75^{\text {th }}\right)$ & $\mathrm{P}$ \\
\hline \multirow{9}{*}{$\begin{array}{l}\mathrm{G} \\
(\mu \mathrm{g} \text { LBSA/g sample) }\end{array}$} & 5 & cow's milk* & $3.77(3.12 ; 3.93)$ & \\
\hline & 5 & yogurt $3.2 \%$ & $7.49(6.74 ; 7.85)$ & 0.008 \\
\hline & 5 & yogurt $2.8 \%$ & $7.02(6.52 ; 7.30)$ & 0.008 \\
\hline & 5 & sour cream $20 \%$ & $6.67(5.93 ; 6.78)$ & 0.008 \\
\hline & 5 & sour cream $12 \%$ & $6.43(6.04 ; 7.36)$ & 0.008 \\
\hline & 5 & sour milk $3.2 \%$ & $5.17(4.60 ; 5.42)$ & 0.008 \\
\hline & 5 & kefir $3.2 \%$ & $5.18(4.91 ; 5.78)$ & 0.008 \\
\hline & 5 & acidophilus milk $3.2 \%$ & $6.32(6.05 ; 6.80)$ & 0.008 \\
\hline & 5 & cow's cheese & $5.26(5.23 ; 6.17)$ & 0.008 \\
\hline \multirow{9}{*}{$\begin{array}{l}\text { SGP } \\
(\mu \mathrm{g} \text { PBSA/g sample) }\end{array}$} & 5 & cow's milk** & $11.22(10.68 ; 11.53)$ & \\
\hline & 5 & yogurt $3.2 \%$ & $10.97(10.81 ; 11.29)$ & 0.841 \\
\hline & 5 & yogurt $2.8 \%$ & $10.31(10.01 ; 10.43)$ & 0.008 \\
\hline & 5 & sour cream $20 \%$ & $14.59(14.20 ; 14.75)$ & 0.008 \\
\hline & 5 & sour cream $12 \%$ & $14.16(13.95 ; 14.59)$ & 0.008 \\
\hline & 5 & sour milk $3.2 \%$ & $10.74(10.55 ; 10.90)$ & 0.222 \\
\hline & 5 & kefir $3.2 \%$ & $10.38(10.09 ; 10.65)$ & 0.032 \\
\hline & 5 & acidophilus milk $3.2 \%$ & $10.49(10.31 ; 10.82)$ & 0.095 \\
\hline & 5 & cow's cheese & $13.63(13.08 ; 13.88)$ & 0.008 \\
\hline
\end{tabular}

G: gangliosides; SGP: sialoglycoproteins; N: sample number; M: median; IQR: interquartile range; *: comparison of dairy products and cow's milk; **: comparison of dairy products and cow's milk; LBSA: total gangliosides expressed as lipid bound sialic acid; PBSA: total sialoglycoproteins expressed as protein bound sialic acid

\section{Conclusions}

The concentration of total gangliosides in dairy products was significantly higher than concentration in cow's milk. The highest concentration of gangliosides was found in yogurt with $3.2 \%$ of milk fat. Since this study determined the concentrations of total gangliosides, future research on the gangliosides profile in dairy products should be conducted.

This research was financed by the Ministry of Science, Education and Sports of Croatia. I would like to thank Professor M. MESARIĆ for the advice during the research.

\section{References}

Castro-Gomez, P., Garcia-Serrano, A., Visioli, F. \& Fontecha, J. (2015): Relevance of dietary glycerophospholipids and sphingolipids to human health. Prostag. Leukot. Ess., 101, 41-51.

Crichton, G.E., Elias, M.F., Dore, G.A. \& RobiIns, M.A. (2012): Relation between dairy food intake and cognitive function: The Maine-Syracuse longitudinal study. Int. Dairy J., 22, 15-23. 
Garcia, C., Antona, C., Robert, B., Lopez, C. \& Armand, M. (2014): The size and interfacial composition of milk fat globules are key factors controlling triglycerides bioavailability in simulated human gastro-duodenal digestion. Food Hydrocolloid., 35, 494-504.

Jensen, R.G. \& Newburg, D.S. (1995): Milk lipids. -in: Jensen, R.G. (Ed.) Handbook of milk composition, Academic Press, New York, pp. 543-572.

Jourdian, G.W., Dean, L. \& Roseman, S. (1971): The sialic acids. XI. A periodate-resorcinol method for the quantitative estimation of free sialic acids and their glycosides. J. Biol. Chem., 246, 430-435.

Kolter, T. (2012): Ganglioside biochemistry. ISRN Biochem, 2012, 1-36. Article ID 506160.

Kuchta, A.M., Kelly, P.M., Stanton, C. \& Devery, R.A. (2012): Milk fat globule membrane - a source of polar lipids for colon health? A review. Int. J. Dairy Technol., 65(3), 315-333.

LedeEn, R.w. \& Yu, R.K. (1982): Gangliosides: structure, isolation, and analysis. Methods Enzymol., 83, $139-191$.

Lee, H., German, J.B., KJelden, R., Lebrilla, C.B. \& Barile, D. (2013): Quantitative analysis of gangliosides in bovine milk and colostrum-based dairy products by ultra-high performance liquid chromatography-tandem mass spectrometry. J. Agr. Food Chem., 61(40), 9689-9696.

Lopez, C. (2005): Focus on the supramolecular structure of milk fat in dairy products. Reprod. Nutr. Dev., 45, 497511.

Lopez, C., Cauty, C. \& Guyomarc'H, F. (2015): Organization of lipids in milks, infant milk formulas and various dairy products: role of technological processes and potential impacts. Dairy Sci. Technol., 95, 863-893.

Mcjarrow, P., Schnell, N., Jumpsen, J. \& Clandinin, T. (2009): Influence of dietary gangliosides on neonatal brain development. Nutr. Rev., 67, 451-463.

NoH, S.K. \& Koo, S.I. (2004): Milk sphingomyelin is more effective than egg sphingomyelin in inhibiting intestinal absorption of cholesterol and fat in rats. J. Nutr., 134(10), 2611-2616.

Pfeuffer, M. \& Schrezenmeir, J. (2001): Dietary sphingolipids: Metabolism and potential health implications. Kieler Milchw. Forsch., 53, 31-42.

Possemiers, S., Van Camp, J., Bolca, S. \& Verstraete, W. (2005): Characterization of the bactericidal effect of dietary sphingosine and its activity under intestinal conditions. Int. J. Food Microbiol., 105, 59-70.

Rombaut, R., Van Camp, J. \& Dewettinck, K. (2006): Phospho- and sphingolipid distribution during processing of milk, butter and whey. Int. J. Food Sci. Tech., 41, 435-443.

Schmelz, E.M., Sullards, M.C., Dillehay, D.L. \& Merrill, A.H. (2000): Colonic cell proliferation and aberrant crypt foci formation are inhibited by dairy glycosphingolipids in 1,2-dimethylhydrazine treated CF1 mice. $J$. Nutr., 130, 522-527.

SchnaAr, R.L., Gerardy-Schahn, R. \& Hilderbrant, H. (2014): Sialic acid in the brain: Gangliosides and polysialic acid in nervous system development, stability, disease, and regeneration. Physiol. Rev., 94, 461-518.

Svennerholm, L. (1957): Quantitative estimation of sialic acids: II A colorimetric resorcinol-hydrochloric acid method. Biochim. Biophys. Acta, 24, 604-611.

Vesper, H., Schelma, E., Nikolova-Karakashion, M.n., Dilllehay, D.l., Lynch, D.V. \& Merrill, A.H. (1999): Sphingolipids in food and the emerging importance of sphingolipids to nutrition. J. Nutr., 129, 1239-1249. 